\title{
KEEFEKTIFAN PEMBELAJARAN DENGAN MENGGUNAKAN PENDEKATAN PBL DAN CTL DITINJAU DARI KEMAMPUAN PEMECAHAN MASALAH DAN MOTIVASI BELAJAR
}

\author{
Husnul Laili \\ STIT Palapa Nusantara Lombok NTB \\ Husnullaili29@gmail.com
}

\begin{abstract}
This study aimed to describe: 1) the effectiveness of the PBL (Problem based Learning) and CTL (contekstual teaching and learning) in terms of students' problem solving ability and motivation to learn mathematics; 2) the effectiveness of the PBL in comparison with the CTL type of cooperative learning in terms of students' problem solving ability and motivation to learn mathematics. To find out the effectiveness of the PBL and CTL in each variable, the data were analyzed using one-sample t-test at a significance level of 5\%. To compare the effectiveness of the PBL and CTL, the data were analyzed using multivariate T2 Hotelling with the significance level of 5\% and followed up with the univariate analysis using a with criterion bon feroni. The results of the study show that: 1) the PBL and the CTL are effective in terms of students' problem solving ability and motivation to learn mathematics.
\end{abstract}

Keywords: PBL, CTL, Problem solving ability, Motivation to learn mathematics

\begin{abstract}
Abstrak : Penelitian ini bertujuan untuk: 1) Mendeskripsikan keefektifan pembelajaran PBL dan CTL ditinjau dari kemampuan pemecahan masalah dan motivasi belajar matematika; 2) Mendeskripsikan keefektifan pembelajaran PBL dibandingkan dengan CTL ditinjau dari kemampuan pemecahan masalah dan motivasi belajar matematika. Untuk mengetahui keefektifan pembelajaran PBL dan CTL masing-masing variabel, data dianalisis menggunakan uji one sample t-test pada taraf signifikansi 5\%. Kemudian untuk membandingkan keefektifan pembelajaran PBL dan CTL. data dianalisis secara multivariat menggunakan T2 Hotelling dengan taraf signifikansi 5\% dan ditindak lanjuti dengan analisis menggunakan uji t univariat dengan kriteria bonferoni. Hasil penelitian menunjukkan bahwa: Pembelajaran dengan pendekatan PBL dan CTL efektif ditinjau dari kemampuan pemecahan masalah dan motivasi belajar matematika.
\end{abstract}

Kata Kunci : PBL, CTL, Kemampuan pemecahan masalah, Motivasi belajar matematika 


\section{PENDAHULUAN}

Pendidikan diharapkan dapat memperkuat keutuhan bangsa dan Negara Kesatuan Republik Indonesia (NKRI), memberi kesempatan yang sama bagi setiap warga negara untuk berpartisipasi dalam pembangunan, dan memungkinkan setiap warga negara untuk mengembangkan potensi yang dimilikinya secara optimal ${ }^{1}$.

Guru matematika dituntut untuk memahami dan mengembangkan kemampuannya. Cara mengajar dan ketelitian menggunakan strategi yang tepat untuk pengajaran yang bukan hanya mampu membangkitkan semangat belajar siswa tetapi juga dapat membuat siswa berpikir aktif dalam kegiatan pembelajaran. Untuk itu perlu dilakukan upaya untuk meningkatkan motivasi dan prestasi belajar siswa yaitu dengan cara memperbaiki strategi pembelajaran yang digunakan. Kegiatan pembelajaran yang dilakukan tanpa strategi, berarti kegiatan tersebut dilakukan tanpa pedoman dan arah yang jelas. Suatu kegiatan yang dilakukan dengan tanpa pedoman dan arah yang jelas dapat menyebabkan terjadinya penyimpangan yang pada gilirannya dapat mengakibatkan tidak tercapainya tujuan yang digariskan ${ }^{2}$.

Dengan memperhatikan standar kompetensi matematika untuk SMP/MTS tersebut di atas, maka kemampuan pemecahan masalah merupakan faktor yang sangat penting. "problem solving is the cornerstone of school mathematics" ". Ini berarti bahwa pemecahan masalah merupakan prinsip dasar dalam pembelajaran matematika di sekolah. Hal ini, menunjukkan bahwa kompetensi pemecahan masalah merupakan salah satu kompetensi yang penting dalam mempelajari matematika, karena pemecahan masalah merupakan sarana mempelajari ide matematika dan keterampilan matematika.

Berdasarkan hasil penelitian Trends in International Mathematics and Science Study (TIMSS) yang dilaksanakan secara kolaboratif setiap empat tahun sekali menunjukkan bahwa prestasi belajar matematika siswa SMP di Indonesia masih berada dalam kategori rendah. Hasil penelitian TIMSS pada tahun 2003 dan 2007 menunjukkan skor pencapaian prestasi belajar berturut-turut 411, dan 397. Dengan perolehan ranking pada tahun 2003 mendapat ranking 35 dari 46 negara, tahun 2007 mendapat

\footnotetext{
${ }^{1}$ Depdiknas. Peraturan Pemerintah RI Nomor 19,(Standar Nasional Pendidikan ,2019). hlm 54

2 Anissatul Mufarokah. Strategi Belajar Mengajar. (Yogyakarta, Sukses Offset, 2009) hlm 2

${ }^{3}$ NCTM. Principles and standars for school mathematics. (Reston, VA: NCTM.2000) hlm. 182
} 
ranking 36 dari 48 negara, serta pada tahun 2009 mendapat ranking 61 dari 65 negara. Sejalan dengan TIMSS, penelitian yang dilakukan Programme for International Student Assesment (PISA) pada tahun 2007 menunjukan bahwa rata-rata prestasi matematika siswa di Indonesia berada pada posisi 59 dari 67 negara. Oleh karena itu, dapat disimpulkan bahwa prestasi belajar matematika siswa di Indonesia masih rendah.

Keadaan di lapangan juga belum sesuai dengan yang diharapkan. Hasil studi menyebutkan bahwa meski adanya peningkatan mutu pendidikan yang cukup menggembirakan, namun pembelajaran dan pemahaman siswa SMP (pada beberapa materi pelajaran termasuk matematika) menunjukkan hasil yang kurang memuaskan. Pembelajaran cendrung text book oriented. Pembelajaran cenderung abstrak dan dengan metode ceramah sehingga konsep-konsep akademik kurang bisa atau sulit dipahami. Sementara itu kebanyakan guru dalam mengajar masih kurang memperhatikan kemampuan berpikir siswa, atau dengan kata lain tidak melakukan pengajaran bermakna, metode yang digunakan kurang bervariasi, dan sebagai akibatnya motivasi belajar siswa menjadi sulit ditumbuhkan dan pola belajar cenderung menghafal dan mekanistis (PPPG Matematika 2004).

Kenyataan di atas juga ditemui di SMPN 1 Batukliang Utara, berdasarkan hasil observasi awal dan hasil wawancara peneliti dengan guru matematika di sekolah yang bersangkutan diperoleh informasi, bahwa pembelajaran matematika di SMPN 1 Batukliang Utara memiliki masalah di antaranya: kurangnya perhatian siswa saat guru menjelaskan di kelas dan kurangnya kemampuan pemecahan masalah siswa.

Untuk membantu mengatasi masalah-masalah yang disebutkan di atas, maka diperlukan suasana belajar yang aktif, efektif, dan kreatif, dan menyenangkan, agar siswa senantiasa meningkatkan motivasinya dalam belajar matematika. Salah satunya adalah dengan menerapkan pembelajaran dengan pendekatan Problem based learning dan Contextual Teaching and Learning yang merupakan alternative pembelajaran yang potensial dalam meningkatkan kemampuan pemecahan masalah, dan motivasi siswa dalam belajar matematika. Sebagaimana diungkapkan, Peneliti ingin mencoba menerapkan Problem based learning dan Contextual Teaching and Learning dengan harapan agar bisa meningkatkan pemahaman siswa dalam pembelajaran matematika, dengan kata lain memberikan pengaruh positif terhadap kemampuan pemylesaian masalah matematika siswa, karena dalam pembelajaran PBL siswa diarahkan untuk bisa 
menyelesaikan masalah matematika dan mampu mengaitkannya dalam kehidupan sehari-hari. Dalam hal ini, secara tidak langsung, guru menuntut siswa untuk aktif dalam proses pembelajaran.

Menurut peneliti, penerapan Problem based learning (PBL) dan Contextual Teaching and Learning (CTL) dapat dijadikan salah satu upaya dalam menuntun peserta didik untuk bisa meningkatkan motivasi dan kemampuan penyelesaian masalah dalam pembelajaran matematika karena PBL dan CTL mengharuskan siswa untuk menemukan makna dalam kehidupan mereka. Viktor Frank ${ }^{4}$ Mengatakan bahwa "man's search for meaning is the primary motivation in his life... and can be fulfiled by bim alone" yang berarti bahwa pencarian seseorang akan makna adalah motivasi utama hidupnya, dan hanya dapat dipenuhi oleh dirinya sendiri. Berdasarkan pendapat diatas, peneliti mengangkat pembelajaran dengan pendekatan PBL dan CTL dengan harapan dapat meningkatkan motivasi belajar dan yang pada akhirnya bisa meningkatkan kemampuan penyelesaian masalah matematika siswa.

Berdasarkan tujuh prinsip pembelajaran yang harus dikembangkan oleh guru maka dapat diuraikan langkah-langkah pembelajaran sebagai berikut.

1) Menyatakan tujuan utama pembelajaran, yaitu sebuah pernyataan kegiatan siswa yang merupakan gabungan antara kompetensi dasar, materi pokok, dan indikator pencapaian hasil belajar.

2) Merumuskan dengan jelas tujuan umum pembelajaran.

3) Menguraikan secara terperinci media atau sumber pembelajaran yang akan digunakan untuk mendukung kegiatan pembelajaran yang diharapkan.

4) Guru membuat sumber belajar ataupun contoh soal untuk siswa dengan menghubungkan antara setiap konsep dengan kenyataan yang ada pada kehidupan sehari-hari.

5) Merumuskan skenario tahap demi tahap kegiatan yang harus dilakukan oleh siswa dalam melakukan proses pembelajaran.

6) Memberikan kesempatan kepada siswa untuk bertanya dan mengeluarkan pendapat.

${ }^{4}$ Johnson, E. B. Contextual teaching and learning. (California : Corwin Press,Inc. 2002) hlm. 23 
7) Merumuskan dan melakukan sistem penilaian dengan memfokuskan pada kemampuan sebenarnya yang dimiliki oleh siswa baik pada saat berlangsungnya (proses) maupun setelah siswa tersebut selesai pembelajaran.

\section{Keefektifan Pembelajaran}

Terkait dengan keefektifan dalam pembelajaran yang mengacu pada pencapaian tujuan secara tepat berdasarkan kriteria dan indikator yang ditetapkan agar dengan mudah menentukan tingkat pencapaian tujuan. Keefektifan pembelajaran sangat berpengaruh pada bagaimana guru mengajar dan bagaimana murid menerima pelajaran tersebut. terdapat 8 karakteristik guru yang efektif yakni:

1) Teacher having responsibility for ordering activities during the day for pupils, i.e structured teaching. 2) pupils having some responsibility for their work and independence whitin these secions, 3) teacher covering only one curriculum area at a time, 4) High levels of interaction with the whole class, 5) teacher providing ample, challenging work, 6) high level of pupils involvement in tasks, 7) a positive atmosphere in the classroom, and 8) teacher showing high level of praise and encouragement. ${ }^{5}$

Makna dari pernyataan di atas, bahwa terdapat 8 karakteristik guru yang efektif sebagai berikut: 1) guru bertanggung jawab memerintahkan berbagai kegiatan selama jam sekolah, yakni mengajar yang berstruktur; 2) siswa memiliki tanggung jawab atas tugasnya dan bersikap mandiri selama sesi-sesi tugas tersebut; 3) setiap guru hanya mengampu satu mata pelajaran saja, 4) interaksi yang tinggi dengan seluruh kelas; 5) guru memberikan banyak tugas yang menantang; 6) keterlibatan murid yang tinggi diberbagai tugas; 7) atmosfir yang positif di kelas; 8) guru menunjukkan penghargaan dan dorongan yang besar kepada anak didiknya.

Berdasarkan uraian di atas, jika semua bisa terlaksana dengan baik maka keefektifan dalam pembelajaranpun pasti akan lebih mudah untuk dicapai. Adapun salah satu cara untuk mewujudkan suatau pembelajaran yang efektif yaitu dengan penerapan strategi pembelajaran yang tepat, diantaranya yaitu dengan penerapan pembelajaran dengan pendekatan PBL dan CTL pada pembelajaran matematika.

5 Muijs, D., \& Reynolds, D. Effective teaching evidence and practice. (2 ${ }^{\text {nd }}$ ed.). (London: SAGE Publication.2005) hlm.2 - 3 
Secara umum, pembelajaran yang efektif ditunjukkan dengan pencapaian tingkat yang melebihi standar ketuntasan belajar siswa. Suatu pembelajaran bisa dikatakan efektif apabila siswa yang memenuhi standar ketuntasan belajar sama dengan 75\% atau melebihi 75\% pada masing-masing kelas. Adapun ketuntasana belajar bergantung dari standar KKM yang ada pada sekolah tempat penelitian, khususnya standar KKM pada pelajaran matematika.

\section{Langkah-langkah Problem-Based Learning (PBL)}

Peran guru dalam PBL adalah menyodorkan berbagai masalah autentik, memfasilitasi

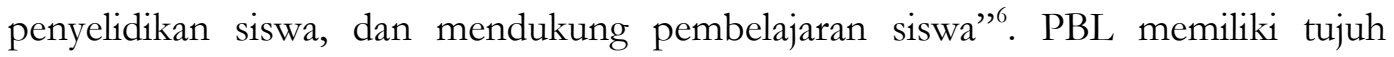
langkah anatara lain sebagai berikut.

1) Mengklarifikasi istilah dan konsep yang belum jelas

Memastikan setiap anggota memahami berbagai istilah dan konsep yang ada dalam masalah. Langkah pertama ini dapat dikatakan tahap yang membuat setiap peserta berangkat dari cara memandang yang sama atas istilah-istilah atau konsep yang ada dalam masalah.

2) Merumuskan masalah

Fenomena yang ada dalam masalah manurut penjelasan hubungan hubungan apa yang terjadi diantara fenomena itu. Kadang-kadang ada hubungan yang masih belum nyata antar fenomena, atau ada yang sub-sub masalah yang harus diperjelas dahulu.

3) Menganalisis masalah

Anggota mengeluarkan pendapat terkait dengan apa yang telah didiskusikan bersama dengan teman kelompok. Terjadi diskusi yang membahas informasi faktual (yang tercantum pada masalah), informasi yang ada dalam pikiran anggota. Brainstorming (curah gagasan) dilakukan dalam tahap ini. Anggota kelompok mendapatkan kesempatan melatih bagaimana menjelaskan dan melihat alternatif atau hipotesis yang terkait dengan masalah.

${ }^{6}$ Arends, I. R. Learning to teach. (Terjemahan Helly Prajitno Soetjipto \& Sri Mulyantini Soetjipto). (New York: McGraw Hill Companies, 2007) hlm. 41 
4) Menata gagasan dan secara sistematis menganalisisnya dengan dalam Bagian yang sudah dianalisis dilihat keterkaitannya satu sama lain, dikelompokkan; mana yang saling menunjang, mana yang bertentangan, dan sebagainya.

5) Memformulasikan tujuan pembelajaran

Kelompok dapat merumuskan tujuan pembelajaran karena kelompok sudah tahu pengetahuan mana yang masih kurang, dan mana yang masih belum jelas. Tujuan pembelajaran akan dikaitkan dengan analisis masalah yang dibuat. Inilah yang akan menjadi dasar gagasan yang akan dibuat di laporan. Tujuan pembelajaran ini juga yang dibuat menjadi dasar penugasan-penugasan individu pada setiap kelompok.

6) Mencari informasi tambahan dari sumber yang lain (diluar diskusi kelompok)

Saat ini kelompok sudah tahu informasi apa yang tidak dimiliki dan sudah punya tujuan pembelajaran. Kini saatnya mereka harus mencari informasi tambahan itu dan menentukam dimana hendak dicarinya. Mereka harus mengatur jadwal dan menentukan sumber informasi. Semua anggota harus mampu belajar sendiri dengan efektif untuk tahapan ini, agar mendapatkan informasi yang relevan, seperti misalnya menentukan kata kunci dalam pemilihan, memperkirakan topik, penulis, publikasi dari sumber pembelajaran. Siswa harus memilih, meringkas sumber pembelajaran itu dengan kalimatnya sendiri (ingatkan mereka untuk tidak hanya memindahkan kalimat dari sumber), dan mintalah menulis sumbernya dengan jelas. Keaktifan setiap anggota harus terbukti dengan laporan yang harus disampaikan oleh setiap individu/subkelompok yang bertanggung jawab atas setiap tujuan pembelajaran. Laporan ini harus disampaikan dipertemuan kelompok berikutnya.

7) Mensintesis (menggabungkan) dan menguji informasi baru, dan membuat laporan untuk guru ${ }^{7}$

Dari laporan-laporan individu/subkelompok yang dipresentasikan dihadapan anggota kelompok lain, kelompok akan mendapatkan informasi-informasi baru. Anggota yang mendengar laporan harus kritis tentang laporan yang disajikan. 7 Taufiq Amir. Inovasi Pendidikan Melalui Problem Based Learning. (Jakarta: prenada media group.2010)
hlm.24 
Pada langkah 7 ini kelompok sudah dapat membuat sintesis; menggabungkannya dan mengombinasikan hal-hal yang relevan. Sebagian bagus tidaknya aktivitas PBL kelompok, akan sangat ditentukan pada tahap ini (untuk kondisi kelas-kelas yang ada di indonesia umumnya proses ini harus terjadi diluar kelas).

Ditahap ini, keterampilan yang dibutuhkan adalah bagaimana meringkas, mendiskusikan, dan meninjau ulang hasil diskusi untuk nantinya disajikan dalam bentuk makalah. Disinilah kemampuan menulis (komunikasi tertulis) sangat dibutuhkan dan sekaligus dikembangkan.

Dengan memperhatikan kegiatan pada setiap tujuh langkah proses PBL, para siswa menggunakan banyak waktunya untuk mendiskusikan masalah, merumuskan hipotesis, menentukan fakta yang relevan, mencari informasi, dan mendefinisikan isi pembelajaran itu sendiri. Tidak seperti pembelajaran tradisional, tujuan pembelajaran dalam PBL tidak ditetapkan dimuka. Sebaliknya, setiap anggota kelompok akan bertanggung jawab untuk membangun isi-isu atau tujuan berdasarkan analisa kelompok tentang permasalahan yang diberikan.

\section{Komponen dalam CTL}

Johnson mengatakan bahwa sistem pembelajaran kontekstual mencakup delapan komponen, yaitu:

1) making meaningful connections, yaitu pembelajaran ditujukan untuk dapat menghubungkan yang bermakna antara ilmu yang diperoleh dengan kehidupan sehari-hari;

2) doing significant work, yaitu dalam pembalajaran, kegiatan yang dilakukan adalah kegiatan yang berarti atau biasa terjadi dalam kehidupan;

3) self-regulated learning, yaitu siswa dapat mangatur diri sendiri untuk belajar dan mendapatkan pengalaman;

4) collaborations, yaitu siswa diajak untuk dapat saling bekerja sama dalam memecahkan suatu masalah dalam proses pembelajaran;

5) critical and creative thinking, yaitu siswa dilatih untuk dapat berpikir kritis dan kreatif dalam menghadapi suatu masalah;

6) nurturing the individual yaitu guru tidak hanya mentrasfer ilmu saja melainkan medidik, melatih, dan memperdulikan siswa dalam proses pembelajaran; 
7) reaching high standards yaitu siswa dilatih untuk mencapai hasil yang maksimal dalam belajar;

8) using authentic assessment yaitu guru memberikan nilai berdasarkan kenyataan yang sebenarnya ${ }^{8}$.

Berdasarkan komponen pembelajaran kontekstual, maka dapat dipaparkan secara singkat makna yang ditujukkan: (1) membuat keterkaitan-keterkaitan yang bermakna, (2) melakukan pekerjaan yang berarti, (3) melakukan pembelajaran yang diatur sendiri, (4) melakukan kerja sama, (5) berpikir kritis dan kreatif, (6) membantu individu untuk tumbuh dan berkembang, (7) mencapai standar yang tinggi, (8) menggunakan penilaian autentik.

\section{METODE PENELITIAN}

Penelitian ini adalah penelitian eksperimen semu (Quasi Eksperiment). Peneliti menggunakan kelompok-kelompok untuk perlakuan karena peneliti tidak dapat memilih individu-individu secara acak. Kelompok-kelompok yang diberikan perlakuan adalah siswa kelas VII yang ada di SMPN 1 Batukliang Utara Lombok Tengah.

Desain penelitian yang digunakan adalah Quasi-Experiments dengan desain pretest-posttest nonequivalent group design. Kelompok I diberi perlakuan dengan pembelajaran PBL dan kelompok II diberi perlakuan dengan pembelajaran CTL. Pada kedua kelompok tersebut dilakukan pretes dan posttes.

\section{Teknik Pengumpulan Data}

Dalam penelitian ini, data diperoleh langsung oleh peneliti dengan memberikan perlakuan kepada kelas eksperimen. Dengan demikian, data penelitian ini merupakan data primer. Teknik pengumpulan data yang dimaksud adalah caracara atau tahapan yang dilalui dalam pengumpulan data. Teknik pengumpulan data dengan tes untuk mengukur kemampuan pemecahan masalah matematika dan non tes untuk mengukur motivasi belajar matematika siswa dengan tahapan sebagai berikut.

${ }^{8}$ Johnson, E. B. op.cit. .hlm. 24 
1. Menyusun instrumen penelitian (silabus, rencana pelaksanaan pembelajaran, lembar kerja siswa, kisi-kisi soal pretes dan posttes untuk mengukur kemampuan pemecahan masalah matematika dan kisi-kisi item pretes dan posttes untuk mengukur motivasi belajar siswa pada matematika, serta rubrik penskoran sesuai dengan variabel yang akan diteliti).

2. Meminta beberapa dosen ahli untuk memvalidasi instrumen penelitian.

3. Melakukan ujicoba instrumen penelitian.

4. Estimasi reliabilitas instrumen penelitian.

5. Revisi instrumen penelitian.

6. Memberikan pretes kepada kedua kelompok siswa di masing-masing kelas.

7. Melaksanakan penelitian secara bersama-sama dengan guru di sekolah.

8. Memberikan posttest kepada sampel penelitian.

\section{Instrumen Penelitian}

Instrumen yang digunakan dalam penelitian ini adalah sebagai berikut.

a. Instrumen Tes

Tes digunakan untuk mengukur kemampuan pemecahan masalah matematika siswa yang berupa tes tertulis yang berbentuk uraian (essay). Tes essay memberikan indikasi yang baik untuk mengungkapkan kemampuan pemecahan masalah matematika. Instrumen tes dalam penelitian ini terdiri atas soal pretest dan posttest berbentuk uraian yang digunakan untuk mengukur kemampuan awal sebelum perlakuan dan setelah perlakuan. Kisi-kisi instrumen pretest dan posttest disajikan pada tabel berikut ini.

Kisi-Kisi Instrumen Pretest dan Posttest Prestasi Belajar Matematika

\begin{tabular}{|c|c|c|}
\hline $\begin{array}{c}\text { Kompetensi } \\
\text { Dasar }\end{array}$ & Indikator soal & $\begin{array}{l}\text { Nomor } \\
\text { soal }\end{array}$ \\
\hline $\begin{array}{l}4.1 \text { Memahami } \\
\text { pengertian dan } \\
\text { notasi himpunan } \\
\text { serta }\end{array}$ & $\begin{array}{l}\text { 1. Siswa dapat menyebutkan anggota } \\
\text { dan bukan anggota suatu himpunan. } \\
\text { 2. Siswa mengenal himpunan kosong } \\
\text { dan notasinya. } \\
\text { 3. Siswa dapat menyatakan notasi suatu } \\
\text { himpunan. }\end{array}$ & $\begin{array}{l}3 \\
2\end{array}$ \\
\hline
\end{tabular}




\begin{tabular}{|c|c|c|}
\hline $\begin{array}{l}4.2 \text { Memahami } \\
\text { konsep himpunan } \\
\text { bagian. }\end{array}$ & $\begin{array}{l}\text { 1. Siswa dapat menentukan banyaknya } \\
\text { himpunan bagian suatu himpunan. } \\
\text { 2. Siswa mengetahui pengertian } \\
\text { himpunan semesta serta dapat } \\
\text { menyebutkan anggotanya. }\end{array}$ & 4 \\
\hline & Total & 5 \\
\hline
\end{tabular}

b. Instrumen Non Tes

Angket motivasi belajar digunakan untuk mengetahui bagaimana motivasi belajar siswa dalam pembelajaran matematika, model skala motivasi yang digunakan dalam penelitian ini adalah skala likert yang terdiri atas lima yaitu: selalu, sering, kadang-kadang, jarang, dan tidak pernah. Kisi-kisi instrumen motivasi belajar siswa disajikan pada tabel berikut.

Kisi-kisi Instrumen Motivasi Belajar Siswa terhadap Matematika

\begin{tabular}{|l|l|l|}
\hline Dimensi & \multicolumn{1}{|c|}{ Indikator Item } & \multicolumn{1}{c|}{ No Item } \\
\hline $\begin{array}{l}\text { Motivasi } \\
\text { Intrinsik }\end{array}$ & $\begin{array}{l}\text { a. Hasrat atau keinginan } \\
\text { berhasil. } \\
\text { b. Harapan atau cita-cita asa } \\
\text { depan. }\end{array}$ & $1^{+}, 2,3,4^{-}, 5^{+}$ \\
\hline $\begin{array}{l}\text { Motivasi } \\
\text { Ekstrinsik }\end{array}$ & $\begin{array}{l}\text { a. Penghargaan dalam belajar. } \\
\text { b. Kegiatan yang menarik } \\
\text { dalam belajar. }\end{array}$ & $18^{+}, 9^{-}$ \\
$13^{+}, 14^{+}, 12^{+}$ \\
\hline \multicolumn{1}{|c|}{ Jumlah } & 15 \\
\hline
\end{tabular}

Penskoran untuk item positif yaitu skor lima untuk respons selalu, skor empat untuk respons sering, skor tiga untuk respons kadang-kadang, skor dua untuk respons jarang, dan skor satu untuk respons tidak pernah. Penskoran untuk item negatif yaitu skor satu untuk respons selalu, skor dua untuk respons sering, skor tiga untuk respons kadang-kadang, skor empat untuk respons jarang, dan skor lima untuk respons tidak pernah. 


\section{Teknik analisis data}

Setelah data pada penelitian ini terkumpul, langkah selanjutnya adalah analisis data untuk menguji hipotesis. Teknik analisis data yang digunakan adalah analisis yang dapat digunakan untuk menguji hipotesis. Alat yang digunakan untuk menganalisis data dan keperluan pengujian hipotesis dalam penelitian ini adalah analisis statistik untuk melihat pengaruh PBL dan CTL terhadap motivasi dan kemampuan pemecahan masalah matematika menggunakan 3 tahap yaitu:

\section{Analisis Keefektifan}

Keefektifan model pembelajaran ditentukan berdasarkan kriteria ketuntasan belajar matematika (KKM) di SMP Negeri 1 Batukliang Utara Kabupaten Lombok Tengah yaitu siswa dikatakan tuntas belajar apabila mencapai nilai minimal 60,00 untuk skala 100, maka kriteria pencapaian tujuan pembelajaran aspek prestasi matematika ditetapkan yaitu 60,00.

Kategori keefektifan model pembelajaran aspek afektif yaitu motivasi belajar siswa terhadap matematika diperoleh dengan menggunakan instrumen non-tes yang berbentuk checklist dengan skala likert. Data yang diperoleh digolongkan dalam kriteria berdasarkan tabel untuk motivasi belajar siswa terhadap matematika. Penskoran untuk skala motivasi belajar matematika pada penelitian ini memiliki rentang antara 15 sampai dengan 75 . Untuk menentukan kriteria hasil pengukurannya digunakan klasifikasi berdasarkan rata-rata ideal (Mi) dan standartjm Deviasi ideal (Si). Mi = $(15$ $+75) / 2=45$ dan $\mathrm{Si}=(75-15) / 6=10$. Adapaun kategirisasi motivasi belajar siswa menurut Saifuddin Azwar ${ }^{9}$, selengkapnya dapat dilihat pada Tabel berikut.

Kategorisasi Motivasi Belajar Siswa

\begin{tabular}{|l|c|c|c|}
\hline No & Interval & Skor $(\mathbf{X})$ & Kriteria \\
\hline 1 & $\mathrm{Mi}+1,5 \mathrm{Si}<\mathrm{X} \leq \mathrm{Mi}+3 \mathrm{Si}$ & $60<\mathrm{X} \leq 75$ & Sangat Tinggi \\
\hline 2 & $\mathrm{Mi}+0,5 \mathrm{Si}<\mathrm{X} \leq \mathrm{Mi}+1,5 \mathrm{Si}$ & $50<\mathrm{X} \leq 60$ & Tinggi \\
\hline 3 & $\mathrm{Mi}-0,5 \mathrm{Si}<\mathrm{X} \leq \mathrm{Mi}+0,5 \mathrm{Si}$ & $40<\mathrm{X} \leq 50$ & Sedang \\
\hline 4 & $\mathrm{Mi}-1,5 \mathrm{Si}<\mathrm{X} \leq \mathrm{Mi}-0,5 \mathrm{Si}$ & $30<\mathrm{X} \leq 40$ & Rendah \\
\hline 5 & $\mathrm{Mi}-3 \mathrm{Si} \leq \mathrm{X} \leq \mathrm{Mi}-1,5 \mathrm{Si}$ & $15 \leq \mathrm{X} \leq 30$ & Sangat Rendah \\
\hline
\end{tabular}

${ }^{9}$ Saifuddin Azwar. Tes Prestasi. (Yogyakarta: Pustaka Pelajar, 2010) hlm.163 
Setelah memperoleh data pengukuran motivasi belajar matematika, skor total masing-masing unit dikategorikan berdasarkan kriteria pada tabel di atas. Total skor semua unit yang telah terkumpul kemudian dihitung presentasenya untuk masingmasing kategori sangat tinggi, tinggi, sedang, rendah, dan sangat rendah.

Selanjutnya dilakukan uji one sample t-test dengan menggunakan bantuan SPSS 16 for windows yaitu untuk melihat keefektifan keseluruhan model pembelajaran terhadap prestasi belajar matematika dan motivasi belajar siswa terhadap matematika. Untuk melakukan uji one sample t-test jika data berdistribusi normal. Rumus yang digunakan adalah sebagai berikut.

$$
\mathrm{t}=\frac{\bar{x}-\mu_{o}}{\frac{s}{\sqrt{n}}}
$$

Keterangan:

$\bar{x}$ adalah nilai rata-rata sampel

$\mathrm{M}_{0}$ adalah nilai yang dihipotesiskan

$S$ adalah standar deviasi sampel

$n$ adalah ukuran sampel ${ }^{10}$

Kriteria keputusannya adalah $\mathrm{H}_{0}$ ditolak jika nilai signifikansi lebih kecil dari 0,05 .

\section{Komparasi Model Pembelajaran}

Untuk menyelidiki perbedaan keefektifan pembelajaran dengan pendekatan PBL dan CTL ditinjau motivasi dan kemampuan pemecahan masalah siswa terhadap matematika dilakukan dengan uji multivariat kemudian dilanjutkan uji univariat yaitu uji t untuk menentukan variabel mana yang berkontribusi terhadap perbedaan keseluruhan. Adapun tahapan pengujian adalah sebagai berikut.

\section{Uji Normalitas}

Uji normalitas dilakukan untuk mengetahui apakah populasi berdistribusi normal atau tidak. Dalam penelitian ini uji normalitas dilakukan terhadap skor pre-test dan skor post-test prestasi dan motivasi belajar matematika sebelum dan sesudah perlakuan pada kedua kelas.

10 Tatsuaoka, M. M. Multivariate Analysis: Techniques For Educational And Psychological Research. (Canada: John Wiley \& Sons, Inc. 1971) hlm. 77 
Pengujian normalitas dalam penelitian ini menggunakan jarak mahalanobis dengan pemeriksaan multivariat normal dilakukan dengan cara membuat $q-q$ plot dari $d_{i}^{2}$ dan $q i$. Tahapan-tahapan dalam pembuatan $q-q$ plot adalah sebagai berikut. (1). Menentukan nilai vektor rata-rata $\bar{X}$ dan invers dari matrik varians kovarians $S^{-1}$. (2). Menentukan nilai $d_{i}^{2}$ yang merupakan jarak Mahalanobis setiap pengamatan dengan vektor rata-ratanya: $d_{i}^{2}=\left(X_{i}-\bar{X}\right) S^{-1}\left(X_{i}-\bar{X}\right)^{T}$ dengan $i=1,2, \ldots, n$. (3). Mengurutkan $d_{i}^{2}$ dari yang terkecil hingga terbesar, $d_{(1)}^{2}<d_{(2)}^{2}<\ldots<d_{(n)}^{2}$. (4). Menentukan nilai $q i$ yang didekati dengan $\chi_{p}^{2}\left(\frac{n-i+\frac{1}{2}}{n}\right)$, dengan $p$ adalah derajat kebebasan.(5). Buat scatter plot dengan ordinat $d_{i}^{2}$ dan axis $q i$, yaitu $\left(\chi_{p}^{2}\left(\frac{n-i+\frac{1}{2}}{n}\right)\right.$, $\left.d_{i}^{2}\right)$

Jika plot membentuk pola garis lurus, maka dapat dikatakan bahwa data berdistribusi multivariat normal. Sedangkan kelengkungan menunjukkan penyimpangan dari normalitas. Titik-titik amatan yang jauh dari garis menunjukkan jarak yang besar atau dapat dikatakan bahwa amatan tersebut merupakan outlier ${ }^{11}$.

\section{Uji Homogenitas}

Uji homogenitas digunakan data kondisi awal maupun data kondisi akhir. Uji homogenitas dimaksudkan untuk menguji kesamaan matriks varians-kovarians dari variabel dependen pada penelitian ini. Data yang digunakan adalah data kondisi awal maupun data kondisi akhir. Untuk uji homogenitas terhadap kemampuan pemecahan masalah matematika dan motivasi belajar siswa terhadap matematika secara bersamasama menggunakan Uji Box's $M$. Jika angka signifikansi (probabilitas) yang dihasilkan baik secara bersama-sama maupun secara sendiri-sendiri lebih besar dari 0.05, maka matriks varians-kovarians pada variabel dependen adalah homogen. Uji homogenitas menggunakan bantuan SPSS 16 for windows.

${ }^{11}$ Johnson, Richard A., Wichern, \& Dean W. Applied multivariate statistical analysis. (New jersey: Pearson Prentice Hall. 2007) Hlm.183 


\section{Uji Hipotesis}

1) Uji Multivariat

Untuk analisis dengan multivariat, data yang dianalisis adalah data yang diperoleh dari pretest, posttest, dan angket motivasi sebelum dan setelah treatment. Pengujian hipotesis tahap pertama, dengan hipotesis sebagai berikut.

$\mathrm{H}_{01}$; Tidak terdapat perbedaan keefektifan pembelajaran dengan PBL ditinjau dari motivasi dan kemampuan pemecahan masalah pada siswa.

$\mathrm{H}_{\mathrm{a} 1}$; Terdapat perbedaan keefektifan pembelajaran dengan PBL ditinjau dari motivasi dan kemampuan pemecahan masalah pada siswa.

Secara statistik, hipotesis di atas, dapat disimbolkan sebagai berikut:

$$
\begin{aligned}
& \mathrm{H}_{01}:\left(\begin{array}{l}
\mu_{H P} \\
\mu_{S P}
\end{array}\right)=\left(\begin{array}{l}
\mu_{H M} \\
\mu_{S M}
\end{array}\right) \\
& \mathrm{H}_{\mathrm{a} 1}:\left(\begin{array}{l}
\mu_{H P} \\
\mu_{S P}
\end{array}\right) \neq\left(\begin{array}{l}
\mu_{H M} \\
\mu_{S M}
\end{array}\right)
\end{aligned}
$$

Dimana $\mu_{H P}$ menyatakan rata-rata (mean) dari kemampuan pemecahan masalah matematika siswa dengan menggunakan pembelajaran pendekatan PBL dan $\mu_{S P}$ menyatakan rata-rata (mean) dari kemampuan pemecahan masalah matematika siswa dengan metode yang biasa digunakan oleh guru matematika di sekolah tersebut. Sedangkan $\mu_{H M}$ menyatakan rata-rata (mean) dari motivasi belajar siswa pada matematika dengan menggunakan pembelajran PBL dan $\mu_{S M}$ menyatakan rata-rata (mean) dari motivasi belajar matematika siswa dengan metode yang biasa digunakan oleh guru matematika di sekolah tersebut..

Perhitungan untuk menguji hipotesis di atas, menggunakan uji multivariat. Uji multivariat menggunakan statistik $T^{2}$ Hotelling dengan formula sebagai berikut.

$$
T^{2}=\frac{n_{1} n_{2}}{n_{1}+n_{2}}\left(\overline{y_{1}}-\overline{y_{2}}\right) S^{-1}\left(\overline{y_{1}}-\overline{y_{2}}\right)
$$

keterangan:

$\mathrm{T}^{2}=$ Hotelling Trace 
$\mathrm{n} 1=$ besar sampel dari kelompok PBL

$\mathrm{n} 2$ = besar sampel dari kelompok CTL

$\mathrm{y} 1=$ vektor rerata skor kelompok PBL

y2 = vektor rerata skor kelompok CTL

$\mathrm{S}=$ matriks disperse ${ }^{12}$

Selanjutnya nilai $T^{2}$ ditransformasi untuk memperoleh nilai dari distribusi $F$ dengan menggunakan formula sebagai berikut.

$$
F=\frac{n_{1}+n_{2}-p-1}{\left(n_{1}+n_{2}-2\right) p} T^{2}
$$

Kriteria keputusannya adalah tolak $\mathrm{H}_{01}$ jika $\mathrm{F}_{\text {hitung }}>\mathrm{F}_{\text {tabel }}\left(\mathrm{F}_{0,05, \mathrm{dk} 1, \mathrm{dk} 2}\right)$ derajat bebasnya $\mathrm{dk}_{1}=\mathrm{p}$ dan $\mathrm{dk}_{2}=\mathrm{n}_{1}+\mathrm{n}_{2}-\mathrm{p}-1$. Pengujian dilakukan dengan bantuan SPSS 16.0 for windows sehingga kriteri keputusannya yaitu tolak $\mathrm{H}_{01}$ jika $\mathrm{p}$-value $<$ 0,05. multivariat dalam penelitian ini menggunakan uji Hotelling $T^{2}$. Tujuan menggunakan uji ini adalah untuk mengetahui perbedaan vektor rerata dua populasi.

2). Uji Univariat

Berkaitan dengan uji hipotesis tahap pertama yang menyatakan bahwa terdapat perbedaan keefektifan pembelajaran PBL dan CTL ditinjau dari motivasi kemampuan pemecahan masalah matematika siswa. Jika data berdistribusi normal dan homogen maka dilakukan statistik uji t untuk menentukan variabel yang berkontribusi terhadap perbedaan secara keseluruhan.

Pengujian hipotesis tahap kedua, dengan hipotesis sebagai berikut.

$\mathrm{H}_{02}$; Pembelajaran dengan PBL tidak lebih efektif dibanding pembelajaran CTL ditinjau dari kemampuan pemecahan masalah matematika siswa.

$\mathrm{H}_{\mathrm{a} 2}$; Pembelajaran PBL lebih efektif dibanding pembelajaran CTL ditinjau dari kemampuan pemecahan masalah matematika siswa.

Secara statistik, hipotesis di atas dapat disimbolkan sebagai berikut:

$$
\begin{aligned}
& \mathrm{H}_{02} ; \mu_{H P} \leq \mu_{S P} \\
& \mathrm{H}_{\mathrm{a} 2} ; \mu_{H P}>\mu_{S P}
\end{aligned}
$$

12 Stevens. J. P. Aplied Multivariate Statistics For The Social Sciences (Fith Edition). (London: Lawrence Erlbaum associates Publishers.2009) hlm. 151 
Di mana $\mu_{H P}$ menyatakan rata-rata (mean) dari kemampuan pemecahan masalah matematika dengan menggunakan pembelajaran $P B L$, sedangkan $\mu_{S P}$ menyatakan rata-rata (mean) dari kemampuan pemecahan masalah matematika dengan menggunakan CTL.

Pengujian hipotesis tahap ketiga, dengan hipotesis sebagai berikut.

$\mathrm{H}_{03}$; Pembelajaran PBL tidak lebih efektif dibanding pembelajaran CTL ditinjau dari motivasi belajar siswa pada matematika.

$\mathrm{H}_{\mathrm{a3}}$; Pembelajaran PBL lebih efektif dibanding pembelajaran CTL ditinjau dari motivasi belajar siswa pada matematika.

Secara statistik, hipotesis di atas dapat disimbolkan sebagai berikut.

$$
\begin{aligned}
& \mathrm{H}_{03} ; \mu_{H M} \leq \mu_{S M} \\
& \mathrm{H}_{\mathrm{a} 3} ; \mu_{H M}>\mu_{S M}
\end{aligned}
$$

Dengan $\mu_{H M}$ menyatakan rata-rata (mean) dari motivasi belajar siswa pada matematika dengan menggunakan pembelajaran $P B L$, sedangkan $\mu_{S M}$ menyatakan rata-rata (mean) dari motivasi belajar siswa pada matematika dengan menggunakan pembelajaran CTL, dapat dilakukan menggunakan uji t univariat dengan rumus sebagai berikut.

$$
t=\frac{\overline{x 1}-\overline{x 2}}{\sqrt{\frac{\left.\left(n_{1}-1\right) S_{1}^{2}+\left(n_{2}-1\right) S_{2}^{2}\right)}{n_{1}+n_{2}-2}\left(\frac{1}{n_{1}}+\frac{1}{n_{2}}\right)}}
$$

Keterangan:

$\overline{x_{1}}=$ Nilai rata-rata kelompok $P B L$

$\overline{x_{2}}=$ Nilai rata-rata kelompok CTL

$S_{1}^{2}=$ varian sampel kelompok $P B L$

$S_{2}^{2}=$ varian sampel kelompok CTL

$n$ = banyak anggota sampel. ${ }^{13}$

Kriteria keputusannya adalah $\mathrm{H}_{0}$ ditolak jika $\mathrm{t}_{\text {hitung }} \geq \mathrm{t}_{(0,05 ; \mathrm{n} 1+\mathrm{n} 2-2)}$.

${ }^{13}$ Sugiono Metode Penelitian Kuantitatif Kualitatif dan R \& D. (Bandung: Alfabeta. 2009). Hlm. 197 


\section{HASIL PENELITIAN DAN PEMBAHASAN}

Data hasil tes kemampuan pemecahan masalah matematika

Deskripsi data hasil pretes dan postes

\begin{tabular}{|l|c|c|c|c|}
\hline \multirow{2}{*}{ Deskripsi } & \multicolumn{2}{|c|}{ PBL } & \multicolumn{2}{c|}{ CTL } \\
\cline { 2 - 5 } & Pretest & Postest & Pretest & Postest \\
\hline Rata-rata & 31,07 & 84,57 & 33,33 & 79,95 \\
\hline Standar deviasi & 6,27 & 8,16 & 5,59 & 8,60 \\
\hline Varians & 39,29 & 66,84 & 31,20 & 65,09 \\
\hline Skor maksimum ideal & 43 & 100 & 45 & 100 \\
\hline Skor minimum ideal & 20 & 68 & 24 & 69 \\
\hline Ketuntasan & $0 \%$ & $100 \%$ & $0 \%$ & $100 \%$ \\
\hline Peningkatan ketuntasan & \multicolumn{3}{|c|}{$100 \%$} & \multicolumn{3}{c|}{$100 \%$} \\
\hline
\end{tabular}

Deskripsi data hasil angket motivasi belajar siswa

\begin{tabular}{|c|c|c|c|c|}
\hline \multirow{2}{*}{ Deskripsi } & \multicolumn{2}{|c|}{ PBL } & \multicolumn{2}{c|}{ CTL } \\
\cline { 2 - 5 } & Sebelum & Setelah & Sebelum & Setelah \\
\hline Banyak siswa & 42 & 42 & 42 & 42 \\
\hline Rata-rata & 109,71 & 119,43 & 102,45 & 114,43 \\
\hline Standar deviasi & 11,75 & 11,83 & 5,04 & 10,78 \\
\hline Varians & 138,06 & 139,86 & 25,06 & 65,86 \\
\hline Skor maksimum ideal & 133 & 146 & 112 & 153 \\
\hline Skor minimum ideal & 90 & 100 & $\mathbf{9 3}$ & 100 \\
\hline
\end{tabular}

Frekuensi dan presentase banyak siswa pada tiap-tiap kriteria motivasi belajar siswa terhadap matematika dihitung sebagaimana rentang skor yang telah ditentukan. Distribusi frekuensi dan presentasi motivasi belajar siswa sebelum dan setelah treatment disajikan pada tabel berikut.

Distribusi Frekuensi Motivasi Belajar Siswa

\begin{tabular}{|c|c|c|c|c|c|c|c|c|}
\hline \multirow{2}{*}{ Kriteria } & \multicolumn{3}{|c|}{ Sebelum treatment } & \multicolumn{3}{c|}{ Setelah treatment } \\
\cline { 2 - 9 } & \multicolumn{2}{|c|}{ PBL } & \multicolumn{2}{c|}{ CTL } & \multicolumn{2}{c|}{ PBL } & \multicolumn{2}{c|}{ CTL } \\
\cline { 2 - 9 } & $\mathrm{F}$ & $\%$ & $\mathrm{~F}$ & $\%$ & $\mathrm{~F}$ & $\%$ & $\mathrm{~F}$ & $\%$ \\
\hline Sangat Tinggi & 0 & $0 \%$ & 0 & $0 \%$ & 15 & $36,6 \%$ & 14 & $34,4 \%$ \\
\hline Tinggi & 25 & $58,5 \%$ & 30 & $71,4 \%$ & 24 & $57,1 \%$ & 25 & $58,5 \%$ \\
\hline Sedang & 17 & $41,5 \%$ & 12 & $28,6 \%$ & 3 & $7,1 \%$ & 3 & $7,1 \%$ \\
\hline Rendah & 0 & $0 \%$ & 0 & $0 \%$ & 0 & 0 & 0 & $0 \%$ \\
\hline Sangat Rendah & 0 & $\%$ & 0 & $0 \%$ & 0 & 0 & 0 & $0 \%$ \\
\hline
\end{tabular}


Berdasarkan tabel di atas, dapat dilihat bahwa sebelum diberikan treatment dengan menerapkan PBL, motivasi awal siswa 58,5\% berada pada kriteria tinggi dan 41,5\% berada pada kriteria sedang, kemudian setelah diberikan perlakuan mengalami peningkatan yaitu $36,6 \%$ berada pada kriteria sangat tinggi, 57,1\% berada pada kriteria tinggi dan $7,1 \%$ berada pada kriteria sedang. Sedangkan motivasi awal siswa sebelum diberikan treatment pada kelas CTL adalah 71,4\% berada pada kriteria tinggi dan $28,6 \%$ berada pada kriteria sedang. Kemudian setelah diberikan treatment, motivasi belajar siswa terhadap matematika mengalami peningkatan yaitu 34,4\% berada pada kriteria sangat tinggi, 58,5\% berada pada kriteria tinggi dan 7,1\% berada pada kriteria sedang.

\section{Uji Hipotesis}

Hasil Uji Keefektifan kelas PBL dan CTL

\begin{tabular}{|c|c|c|c|c|c|}
\hline Kelompok & Variabel & $\bar{x}$ & $\boldsymbol{S}$ & $\mathbf{D f}$ & $\mathbf{t}_{\text {hitung }}$ \\
\hline \multirow{2}{*}{ STAD } & KPMM & 84,55 & 8,23 & 41 & 15,395 \\
\cline { 2 - 6 } & Motivasi & 109,71 & 11,75 & 41 & 2,598 \\
\hline \multirow{2}{*}{ CTL } & KPMM & 85,95 & 9,59 & 41 & 14,158 \\
\cline { 2 - 6 } & Motivasi & 119,42 & 11,83 & 41 & 7,905 \\
\hline \multirow{2}{*}{$\mathrm{t}_{\text {tabel }}$} & \multicolumn{5}{|c|}{2,019} \\
\hline
\end{tabular}

Berdasarkan tabel di atas, pada kelompok PBL untuk variabel KPMM (kemampuan pemecahan masalah matematika) diperoleh nilai $t_{\text {hitung }}=15,395$, untuk variabel motivasi belajar siswa terhadap matematika diperoleh nilai $t_{\text {hitung }}=2,598$. Kedua nilai $t_{\text {hitung }}$ ini menunjukkan bahwa hasil yang diperoleh signifikan karena nilai $t_{\text {hitung }}$ tersebut lebih besar dari $t_{\text {tabel }}=2,019$. Dengan demikian, pendekatan PBL efektif ditinjau dari kemampuan pemecahan masalah matematika dan motivasi belajar siswa terhadap matematika.

Pada kelompok CTL untuk variabel KPMM (kemampuan pemecahan masalah matematika) diperoleh nilai $t_{\text {hitung }}=14,158$ untuk variabel motivasi belajar siswa terhadap matematika diperoleh nilai $\mathrm{t}_{\text {hitung }}=7,905$. Kedua nilai $t_{\text {hitung }}$ ini menunjukkan bahwa hasil yang diperoleh signifikankarena nilai-nilai tersebut lebih besar dari $\mathrm{t}_{\text {tabel }}=2,019$. Dengan demikian, sebagaimana model pendekatan dengan pembelajaran PBL, model cooperative learning tipe CTL efektif baik ditinjau dari 
kemampuan pemecahan masalah matematika dan motivasi belajar siswa terhadap matematika.

\section{Uji Multivariat}

Untuk dapat mengetahui kesamaan kelompok PBL dengan CTL dan perbedaan keefektifan kelompok cooperative learning tipe PBL dengan CTL ditinjau dari kemampuan pemecahan masalah dan motivasi belajar siswa dilakukan uji multivariat menggunakan statistik $T^{2}$ Hotellingdengan bantuan program SPSS 16 for windows.

Hasil uji kesamaan kelompok PBL dengan CTL

\begin{tabular}{|c|c|c|c|c|c|}
\hline Efek & Value & $\mathrm{F}$ & $\begin{array}{c}\text { Hypothesis } \\
\mathrm{df}\end{array}$ & Error df & Sig \\
\hline Hotelling's Trace & 0,060 & $2,446^{\mathrm{a}}$ & 2,000 & 81,000 & 0,093 \\
\hline
\end{tabular}

Dari tabel di atas, dapat diketahui bahwa signifikansi yang diperoleh adalah 0,093 dan bernilai lebih dari 0,05. Ini menunjukkan bahwa $\mathrm{H}_{0}$ diterima. Dengan demikian tidak terdapat perbedaan mean antara kelompok PBL dan tipe CTL ditinjau dari kemampuan pemecahan masalah matematika dan motivasi belajar siswa terhadap matematika. Sedangkan hasil uji keefektifan PBL dan CTL setelah treatment dapat dilihat pada tabel berikut

Hasil uji keefektifan kelompok PBL dengan CTL

\begin{tabular}{|c|c|c|c|c|c|}
\hline Efek & Value & F & $\begin{array}{c}\text { Hypothesis } \\
\text { df }\end{array}$ & Error df & Sig \\
\hline Hotelling's Trace & 0,476 & $19,288^{\mathrm{a}}$ & 2,000 & 81,000 & 0,000 \\
\hline
\end{tabular}

Berdasarkan tabel di atas, tampak bahwa F hitung $=19,288$,signifikansi yang diperoleh adalah 0,000 dan bernilai kurang dari 0,05. Ini menunjukkan bahwa $\mathrm{H}_{0}$ ditolak. Dengan demikian, dapat disimpulkan bahwa terdapat perbedaan keefektifan antara kelompok model cooperative learningtipe PBL dan tipe CTL ditinjau dari kemampuan pemecahan masalah dan motivasi belajar siswa terhadap matematika.

Dengan adanya perbedaan secara berkelompok, maka perlu di uji lanjut untuk meyakinkan bahwa kedua kelompok tersebut memang berbeda dengan menggunakan uji t univariat. 


\section{Uji Univariat}

Berdasarkan hasiluji hipotesis multivariat tahap pertama bahwa terdapat perbedaan keefektifan model cooperative learning tipe PBL dan tipe CTL ditinjau dari kemampuan pemecahan masalah matematika dan motivasi belajar siswa terhadap matematika, maka dilakukan uji $\mathrm{t}$ univariat. Hasil analisis terhadap perbedaan kemampuan pemecahan masalah matematika kedua kelompok diperoleh $t_{\text {hitung }}$ sebesar $-0,710$, kemudian $t_{\text {tabel }}$ sebesar 1,989atau $t_{\text {hitung }}=-0,710<t_{0,05,82}=1,989$; sehingga dapat disimpulkan $\mathrm{H}_{0}$ diterima. Dengan kata lain model cooperative learning tipe PBL tidak lebih efektif dari tipe CTL ditinjau dari kemampuan pemecahan masalah matematika.

Untuk motivasi belajar siswa terhadap matematika didapat $t_{\text {hitung }}$ sebesar 3,776 kemudian $\mathrm{t}_{\text {tabel }}$ sebesar 1,989 atau $\mathrm{t}_{\text {hitung }}=3,776>\mathrm{t}_{0,05,82}=1,989$, sehingga dapat disimpulkan $\mathrm{H}_{0}$ ditolak. Dengan demikian model cooperative learning tipe PBL lebih efektif dari tipe CTL ditinjau dari motivasi belajar siswa terhadap matematika.

\section{KESIMPULAN}

Berdasarkan hasil analisis data dan pembahasan, maka dapat disimpulkan bahwa :

Pembelajaran dengan pendekatan PBL sama efektif dengan CTL ditinjau dari kemampuan pemecahan masalah matematika, tetapi model cooperative learning tipe PBL lebih efektif dari CTL ditinjau dari motivasi belajar siswa terhadap matematika.

\section{DAFTAR PUSTAKA}

Anissatul Mufarokah. (2009). Strategi Belajar Mengajar. Yogyakarta : Sukses Offset. Arends, I. R. (2007). Learning to teach. (Terjemahan Helly Prajitno Soetjipto \& Sri Mulyantini Soetjipto). New York: McGraw Hill Companies. (Buku asli diterbitkan tahun 2008)

Depdiknas. (2004). Kurikulum 2004 Sekolah menengah pertama; Mata pelajaran Matematika. Jakarta: Depdiknas.

Johnson, E. B. (2002). Contextual teaching and learning. California : Corwin Press,Inc.

Johnson, Richard A., Wichern, \& Dean W. (2007). Applied multivariate statistical analysis. New jersey: Pearson Prentice Hall.

Joyce, B., Weil, M., \& Calhoun, E. (2004). Model of teaching $\left(7^{\text {th }}\right.$ ed). Boston, MA: Pearson Education. 
Muijs, D., \& Reynolds, D. (2005). Effective teaching evidence and practice. (2 $2^{\text {nd }}$ ed.). London: SAGE Publication.

NCTM. (2000). Principles and standars for school mathematics. Reston, VA: NCTM.

SaifuddinAzwar. (2010). TesPrestasi. Yogyakarta: PustakaPelajar

Stevens. J. P. (2009). Aplied Multivariate Statistics For The Social Sciences (Fith Edition). London: Lawrence Erlbaum associates Publishers.

Sugiono.(2009). Metode Penelitian Kuantitatif Kualitatif dan R \& D. Bandung: Alfabeta. (2011). Statistik Untuk Penelitian. Bandung: Alfabeta.

Tatsuaoka, M. M. (1971). Multivariate Analysis: Techniques For Educational And Psychological Research. Canada: John Wiley \& Sons, Inc.

Taufiq Amir. (2010). Inovasi Pendidikan Melalui Problem Based Learning. Jakarta: prenada media group. 